\title{
Analysis of Damage Evolution Characteristics of Surrounding Rock in Deep Anchorage Cavern under Dynamic Loading
}

\author{
G.Y. Wang ${ }^{1}$, T.T. Wang ${ }^{2}$, S.R. Wang ${ }^{1 *}$, Y.S. He ${ }^{3}$, F.L. Kong ${ }^{3}$, and J.Q. Fan ${ }^{3}$ \\ ${ }^{1}$ International Joint Research Laboratory of Henan Province for Underground Space Development and Disaster Prevention, \\ Henan Polytechnic University, Jiaozuo 454003, China \\ ${ }^{2}$ Huanghe Jiaotong University, Jiaozuo 454950, China \\ ${ }^{3}$ Institute of National Defense Engineering, Academy of Military Sciences, Luoyang 471023, China
}

Received 7 January 2020; Accepted 23 April 2020

\begin{abstract}
The damage of deep anchorage cavern is a key index to judge the stability of underground engineering, but the existing damage analysis of deep anchorage cavern does not consider the influence of dynamic-static coupling and in-situ stress at the same time. To investigate the damage law of the deep anchorage cavern, the damage evolution process of the deep anchorage cavern under top explosion was analyzed by using numerical simulation method, the influence of in-situ stress on that was also explored, and the corresponding failure forms were obtained. Results show that under the top explosion, the tensile and compressive damage to the vault is mainly influenced by the dynamic loading, which of the floor is mainly affected by the static loading. With the increase of hydrostatic confining pressure, the failure mode of the vault is from the overall collapse of the anchoring area to the local peeling off of the free surface of the cavern, and the floor heave becomes more serious. As the lateral pressure coefficient increases, the anchorage cavern is most stable under the hydrostatic pressure, and only the local peeling occurs on the free surface of the cavern arch. When the lateral pressure coefficient is less than 1.0, the local anchoring zone above the anchorage cavern will form penetration directly. When the lateral pressure coefficient exceeds 1.0, the overall collapse may occur from the explosion source to the anchorage cavern. The obtained conclusions can provide the basis and reference for the similar deep cavern support.
\end{abstract}

Keywords: Deep cavern, Dynamic load, Damage evolution, In-situ stress, Numerical analysis

\section{Introduction}

With increase of the demand for resources and energy, the development and utilization of deep underground space become a necessary requirement. Therefore, the safety and stability of the deep underground engineering will become the focus of attention. For the deep underground engineering, the geological structure makes the surrounding rock in a higher initial stress state. The mechanical properties of the surrounding rock of the anchorage cavern are inevitably affected by the high in-situ stress [1-3].

Currently, the deep cavern often suffers the disturbance of the high in-situ stress and dynamic loading at the same time, the stability of the deep cavern under the dynamic disturbance is an unavoidable problem to ensure the safety of the underground engineering. Although many scholars have studied the dynamic response of the anchorage cavern from the perspective of the form and position of dynamic loading and different bolt support designs, the damage analysis of the deep anchorage cavern has not considered the influence of dynamic-static coupling and in-situ stress [4-7].

Since the damage of the deep anchorage caverns is a key indicator to judge the stability of underground engineering, it is very meaningful to study the dynamic response of the deep cavern under dynamic disturbance.

*E-mail address: w_sr88@163.com

ISSN: $1791-2377 @ 2020$ School of Science, HHU. All rights reserved.

doi:10.25103/iestr.133.11

\section{State of the art}

As a convenient and economical underground engineering reinforcement technology, the anchor reinforcement has been widely used in geotechnical engineering such as coal mines, metal mines, water conservancy, tunnels and national defense. Considering the dynamic response of the anchoring projects under dynamic loading, some scholars have done lots of work and achieved many fruitful results.

For the underground engineering built in the shallow depths, the damage of the underground engineering under dynamic load was weakly affected by the in-situ stress. Based on-site monitoring, Singh studied the blast vibration damage to the underground coal mines from the adjacent open-pit blasting [8]. Wang et al. found that the excavation damaged zone around the roadways under the dynamic load was larger than that under the static load [9]. By using physical tests, $\mathrm{Gu}$ et al. researched the dynamic response and damage law of the surrounding rocks and supporting structures of the anchoring cavities under the explosion loading $[7,10,11]$. Wang et al. investigated the mechanical behavior of fully-grouted bolt in jointed rocks subjected to double shear tests [12]. Wang et al. revealed the force mechanism of the bolt under the dynamic loading and he put forward the failure patterns and failure criteria of the anchored bolt of the circular roadway [13]. Compared with the behaviors of three types of fully grouted rockbolts under dynamic loading, Mortazavi \& Fatemeh pointed that the yielding rockbolts were the best choice [14]. Based on the neutral point theory, Zhou et al. proposed a new numerical 
simulation method for the fully grouted bolt under the seismic loading, and they found that the bolts could effectively limit the damage zone and the deformation of the surrounding rock [15]. Deng et al. believed that the boltsupported tunnel subjected to blast-induced shock wave experienced relatively small damage compared to the nonsupported tunnel [16].

Through on-site monitoring, Nick \& Woo found that the failure in the $1150 \mathrm{~m}$ drift would be damaged after numerous successive blasts in an adjacent tunnel, and they proposed the corresponding anti-blasting measures [17]. Ortlepp et al. studied the reinforcement of the large deformation tunnels under the static and dynamic loading, and they pointed out that the yield bolt could absorb a large amount of energy without showing any damage [18]. Wu et al. analyzed the dynamic response characteristic of the deep anchored surrounding rock under the impact loading by the field tests [19]. As stated by Li et al. that the in-situ stress influenced the failure mode, dynamic stress concentration, energy evolution and damage zone of the underground tunnels subjected to the blasting loads [20-22]. Wang et al. investigated the effects of in-situ stress on the damage zone of the underground cavern under the seismic loads [23]. However, most of the existing studies considering dynamicstatic coupling and in-situ stress pay more attention to the dynamic responses of the unsupported cavern.

Although the dynamic response of the anchorage cavern under dynamic loading was studied from the perspective of the form and position of the dynamic load and the different bolt support designs, the high in-situ stress is a key factor that cannot be ignored for studying the deep anchorage cavern. However, there are few studies on the damage evolution of the deep anchorage cavern under dynamic loading considering different in-situ stress. To enrich the stability research of the deep underground engineering under the dynamic loading, based on the model tests, the damage evolution of the deep anchorage cavern under the dynamic load was analyzed by using numerical analysis and the influence of the in-situ stress was discussed also in this study.

The rest of this study is organized as follows. Section 3 describes the relevant research methods. Section 4 presents the results and discussion, and finally, the conclusions are summarized in Section 5.

\section{Research method}

\subsection{Test materials}

The model simulates a straight-wall-arched-top cavern with a depth of $20 \mathrm{~m}$ and a span of 3-5 m under top explosion. The surrounding rocks of the cavern are considered as class III. As shown in Fig. 1, the cavern model is fixed by four rigid devices that are movable forward and backward. According to Froude gravity similarity criterion, the density scale $\mathrm{k}_{\rho}=0.67$, stress scale $\mathrm{k}_{\sigma}=0.06$, and geometric scale $\mathrm{k}_{l}$ $=0.09$ were obtained through dimensional analysis. The model test materials are determined by similar scales as sand, cement, water, and accelerator, and the mixing ratio is $15: 1$ : 1.6: 0.0166 . The size of the model is $2.4 \mathrm{~m} \times 1.5 \mathrm{~m} \times 2.3 \mathrm{~m}$ (length $\times$ width $\times$ height), and a straight-wall-arched-top cavern with a span of $60 \mathrm{~cm}$, a height of $42 \mathrm{~cm}$, and an arch radius of $35 \mathrm{~cm}$ is excavated along the length of the model (Fig. 2). The bolt for reinforcing the surrounding rock is simulated with an aluminum bar with a diameter of $1.84 \mathrm{~mm}$, and a length of $24 \mathrm{~cm}$. The backing plate is made of an aluminum plate with a thickness of $2-3 \mathrm{~mm}$, and the length $\times$ width $=12 \times 12 \mathrm{~mm}$. The nut is a standard $\mathrm{M}_{2}$ nut.

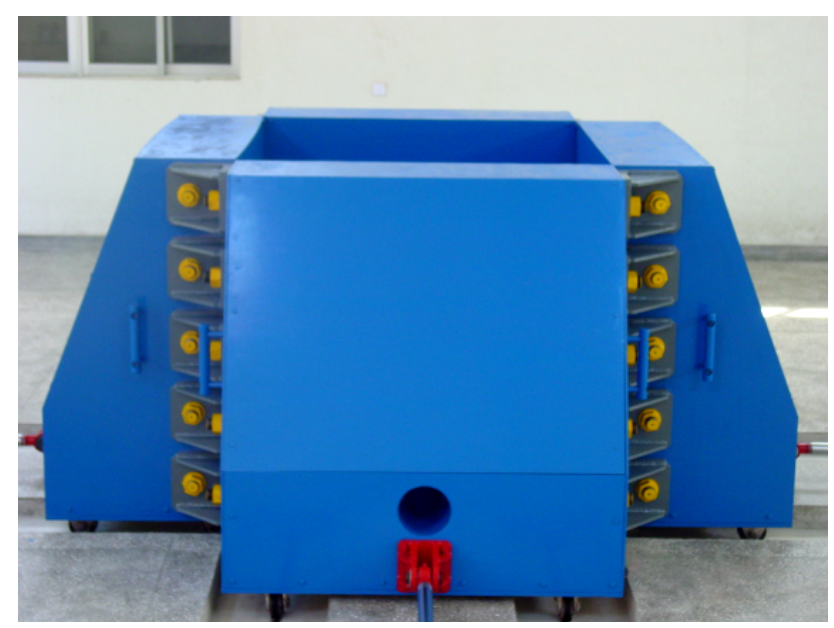

Fig. 1. The model test apparatus 。

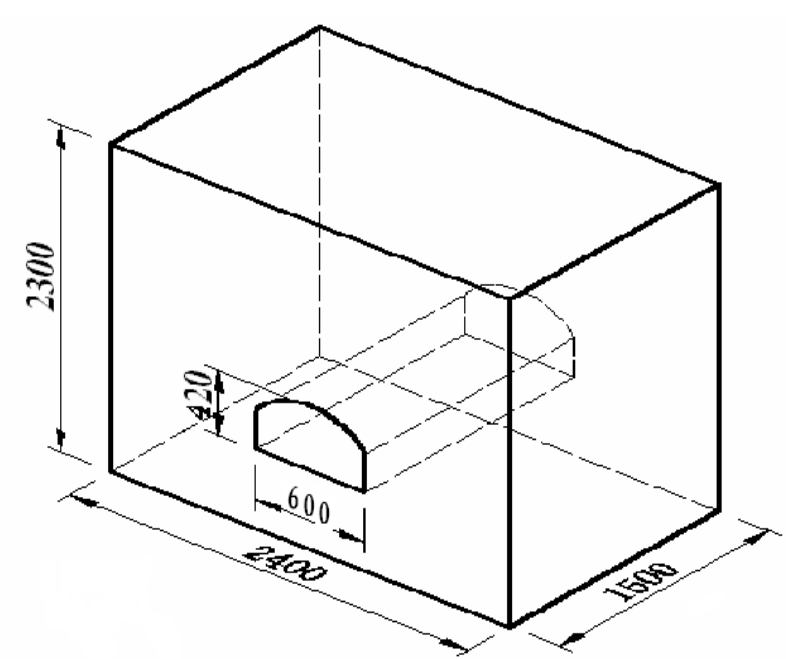

Fig. 2. Test model sizes (unit: $\mathrm{mm}$ ).

\subsection{Numerical simulation method}

\subsubsection{Computation model}

For the similarity model test, the calculation model can be simplified as a plane strain problem, because the axial dimension of the model test is much larger than the radial dimension. Thus, a two-dimension plane calculation model is established, as shown in Fig. 3. The blast loading is achieved by applying the blasting pressure to the inner surface of the explosion chamber with a radius of $10 \mathrm{~cm}, 83$ $\mathrm{cm}$ from the vault of the cavern, and the time historical curve of blasting pressure is shown in Fig. 4. Two monitoring points were set at $20 \mathrm{~cm}$ and $40 \mathrm{~cm}$ directly below the explosion source to monitor the pressure.

The accuracy of the numerical model was verified by the model tests of the two monitoring points. According to the reference [24], to stabilize the peaks and waveforms of various physical quantities during dynamic calculation, the number of grids in a load wavelength is at least $16 \mathrm{~m}$. Combined with the physical parameters of the model materials, the load wavelength is $0.22 \mathrm{~m}$, and the grid size is selected as $10 \mathrm{~mm}$. The boundary conditions on both sides and bottom of the model are set as non-reflection boundary conditions. 


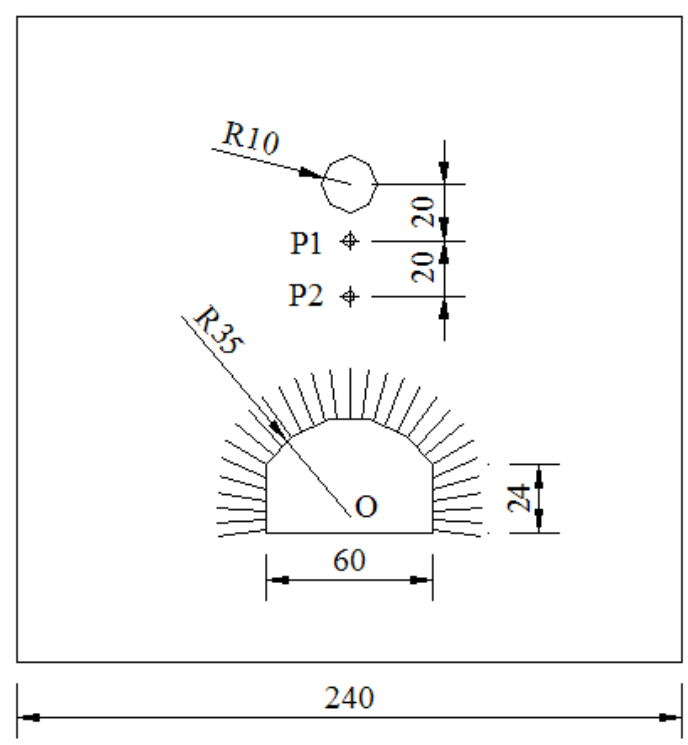

Fig. 3. Model diagram (unit: $\mathrm{cm}$ ).

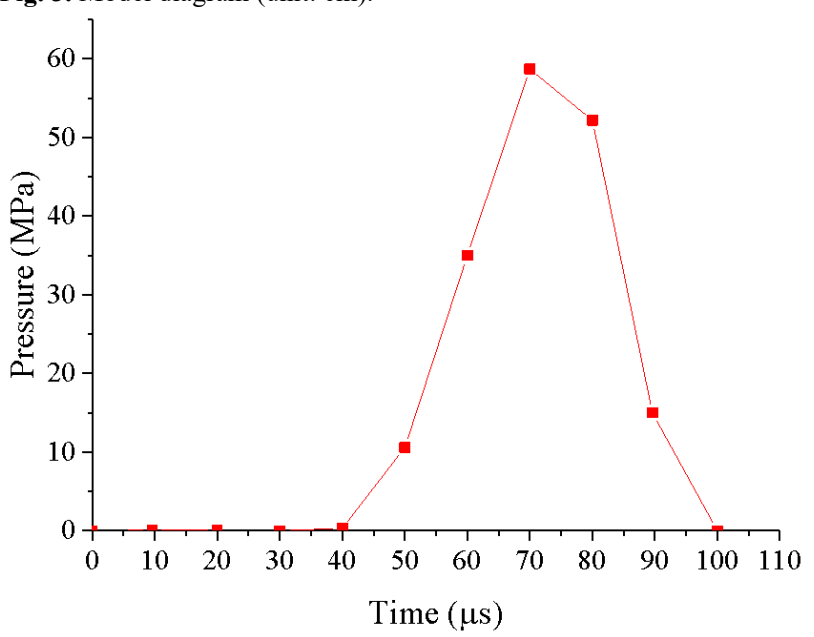

Fig. 4. The time historical curve of blasting pressure.

\subsubsection{Calculated parameters}

To simulate the mechanical behavior of rock materials under the explosive load, the concrete damage plasticity model is utilized, which assumes that the failure of materials is mainly due to tensile cracking and compression cracking, and the evolution of yield or failure surface is controlled by two hardening variables: the equivalent plastic strain $\tilde{\varepsilon}_{\mathrm{t}}^{\mathrm{pl}}$ in tension and the equivalent plastic strain $\tilde{\varepsilon}_{\mathrm{c}}^{\text {pl }}$ in compression.

The damage factor $d$ is determined by the equivalent energy method. According to Sidoroff's principle of energy equivalence, the elastic residual energy generated by the stress acting on the damaged material and the elastic residual energy generated by the non-destructive material are the same in form, as long as the stress is changed to the effective stress or the elastic modulus is changed to the equivalent elastic modulus of the damage.

Elastic residual energy of nondestructive materials:

$$
W_{0}^{e}=\sigma^{2} / E_{0}
$$

Equivalent elastic residual energy of damaged material:

$$
W_{d}^{e}=\sigma^{2} / E_{\mathrm{d}}=\bar{\sigma}^{2} / E_{0}
$$

Effective stress:

$\bar{\sigma}=\sigma /(1-d)$

Therefore:

$d=1-\sqrt{\sigma / E_{0} \varepsilon}$

Where, $E_{0}$ is the lossless elastic modulus. $E_{\mathrm{d}}$ is the lossy elastic modulus. Other parameters of the model are shown in Table 1.

The yield condition of this model was proposed by Lubliner et al. [25] and improved by Lee and Fenves [26]. The expression of the yield function $F\left(\bar{\sigma}, \tilde{\varepsilon}^{\mathrm{pl}}\right)$ is:

$F\left(\bar{\sigma}, \tilde{\varepsilon}^{\mathrm{pl}}\right)=\frac{1}{1-\alpha}\left(\bar{q}-3 \alpha \bar{p}+\beta\left(\bar{\varepsilon}^{\mathrm{pl}}\right)\left\langle\hat{\bar{\sigma}}_{\max }\right\rangle-\gamma\left\langle-\hat{\bar{\sigma}}_{\max }\right\rangle\right)-\bar{\sigma}_{\mathrm{c}}\left(\tilde{\varepsilon}_{\mathrm{c}}^{\mathrm{pl}}\right) \leq 0$

Among them:

$\alpha=\frac{\left(\sigma_{\mathrm{b} 0} / \sigma_{\mathrm{c} 0}\right)-1}{2\left(\sigma_{\mathrm{b} 0} / \sigma_{\mathrm{c} 0}\right)-1}(0 \leq \alpha \leq 0.5)$

$\beta\left(\tilde{\varepsilon}^{\mathrm{pl}}\right)=\frac{\bar{\sigma}_{\mathrm{c}}\left(\tilde{\varepsilon}_{\mathrm{p}}^{\mathrm{pl}}\right)}{\bar{\sigma}_{\mathrm{t}}\left(\tilde{\varepsilon}_{\mathrm{t}}^{\mathrm{pl}}\right)}(1-\alpha)-(1+\alpha)$

$\gamma=\frac{3\left(1-K_{c}\right)}{2 K_{c}-1}, \bar{p}=-\frac{1}{3} I: \bar{\sigma}$

$\bar{q}=\sqrt{\frac{3}{2} \bar{S}: \bar{S}}, \bar{S}=\bar{p} I+\bar{\sigma}$

where, $\alpha$ and $\gamma$ are both dimensionless material constants. $\bar{p}$ is effective hydrostatic pressure. $\bar{q}$ is Mises equivalent effective stress. $\bar{\sigma}$ is the effective stress tensor. $\bar{S}$ is the effective stress deviator. $\sigma_{\mathrm{b} 0}$ is the axial initial yield compressive stress. $\sigma_{\mathrm{c} 0}$ is the non-isoaxial initial yield stress. $K_{c}$ is the parameter characterizing the shape of the yield curve on the plane of the partial stress. $I$ is the identity matrix.

The strain rate of rocks will be large under explosive loads. The strain rate will affect the strength of the rock, and the high strain rate will lag the crack propagation, and the propagation of the stress wave will also change. The relationship between rock strength and strain rate in this paper [27] is as follows:

$\sigma_{\mathrm{d}}=0.4 \sigma_{\mathrm{cd}}(\dot{\varepsilon})^{1 / 3}$

where, $\sigma_{\mathrm{d}}$ is the dynamic strength. $\sigma_{\mathrm{cd}}$ is the static strength. $\dot{\varepsilon}$ is the strain rate. Other parameters of the model are shown in table 1 .

In the similarity test, the bolt was simulated by the aluminum bar, with a diameter of $1.84 \mathrm{~mm}$, density of 3000 $\mathrm{kg} / \mathrm{m}^{3}$, elastic modulus of $76 \mathrm{GPa}$, Poisson's ratio of 0.34 , and the yield strength of $282 \mathrm{GPa}$ by the ideal elastic-plastic model. 
Table 1. Properties of CDP model.

\begin{tabular}{c|c|c|c|c|c|c|c|c}
\hline Density $\left(\mathrm{kg} \cdot \mathrm{m}^{-3}\right)$ & $E(\mathrm{GPa})$ & $\mu$ & Dilation Angle $\left(^{\circ}\right)$ & Eccentricity & $\sigma_{\mathrm{b} 0} / \sigma_{\mathrm{c} 0}$ & $K_{\mathrm{c}}$ & Viscosity Parameter \\
\hline 1800 & 2.03 & 0.16 & 25 & 0.1 & 1.16 & 0.66667 & 0 \\
\hline
\end{tabular}

\section{Results and discussion}

\subsection{Calculation model verification}

Fig. 5 shows the pressure time-history curves of $\mathrm{P}_{1}$ and $\mathrm{P}_{2}$ in similarity model tests and numerical simulations, respectively. It can be seen from Fig. 5, the shape of the pressure curve and the peak value at the same monitoring point are similar. The main difference is that the propagation time of the numerical simulation results is shorter than that of the test results, which is due to the ideal materials in the numerical simulations.

As can be seen from Fig. 6, the most serious damage area of the anchorage cavern is the zone near interface between the vault anchorage and the non-anchorage zones. There are several symmetric trumpet cracks in the nonanchorage zone from the vault to the explosion source, which is basically consistent with the model test results in Fig. 6(b). The establishment of the calculation model and the selection of the material constitutive are reasonable, and the accuracy of the numerical calculation results is guaranteed
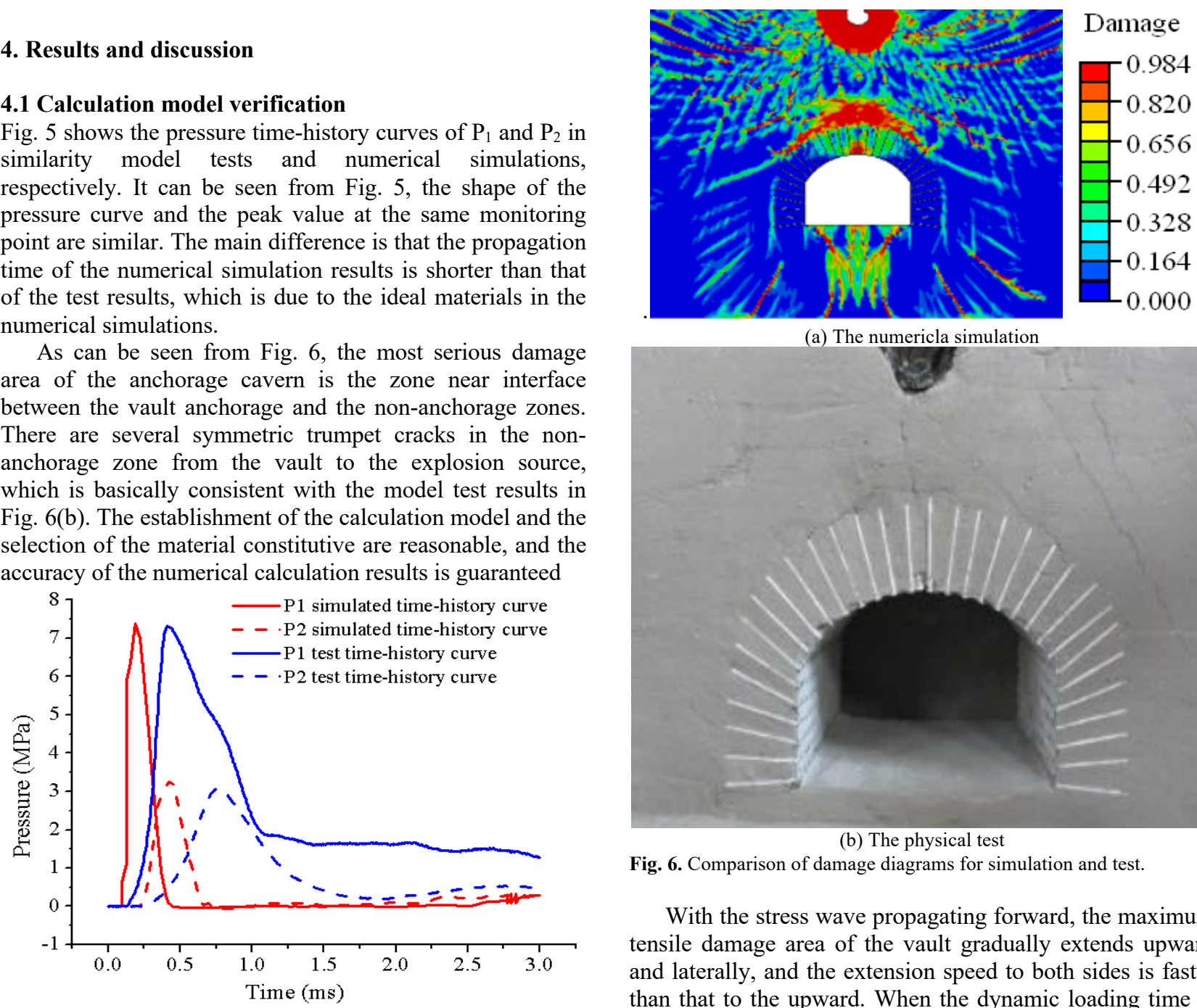

(a) The numericla simulation

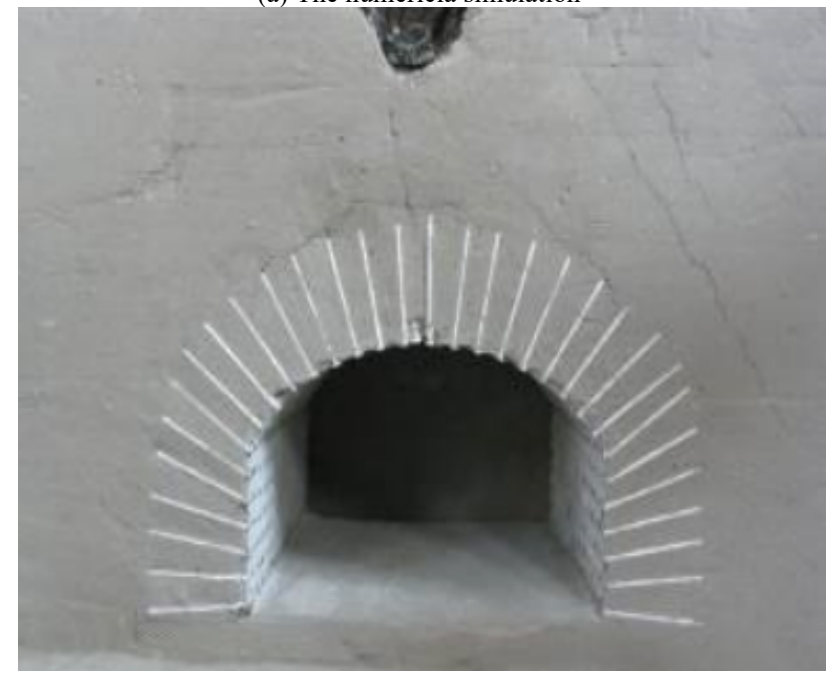

(b) The physical test

Fig. 6. Comparison of damage diagrams for simulation and test.

With the stress wave propagating forward, the maximum tensile damage area of the vault gradually extends upward and laterally, and the extension speed to both sides is faster than that to the upward. When the dynamic loading time is $0.9 \mathrm{~ms}$, the maximum tensile damage begins to appear at the end of the bolt on the vault; meanwhile the head of bolt on the sidewall also appears obvious tensile damage due to the stress wave. When the stress wave is applied for $1.7 \mathrm{~ms}$, the maximum tensile damage area of the vault no longer changes, which mainly occurs in the arch, and the maximum tensile damage area decreases from the vault to the spandrel in order. Maximum tensile damage was found at the ends of the three bolts in the vault. In the whole process of dynamic loading, due to the reflection and diffraction of stress wave, the influence of stress wave on the floor of cavern is very small, and the range and degree of tensile damage of the floor hardly change, which is mainly formed by the static loading.

The compression damage evolution process of the deep anchorage cavern under dynamic load is shown in Fig. 8. As can be seen from Fig. 8, when the stress wave has not yet acted, since the rock's compressive capacity is obviously stronger than the tensile capacity, only two relatively narrow maximum compression damage zones are formed within the range of $30^{\circ}-90^{\circ}$ of the anchorage cavern corner, that is, the damage factor $d$ is greater than or equal to 0.906 and produces weak compressive damage in all bolt heads. 
G.Y. Wang, T.T. Wang, S.R. Wang, Y.S. He, F.L. Kong and J.Q. Fan/

Journal of Engineering Science and Technology Review 13 (3) (2020) 96 - 105

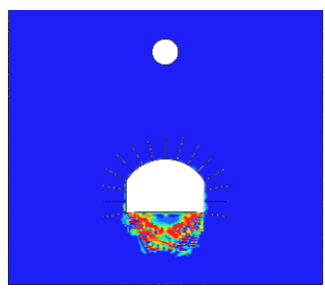

(a) $0 \mathrm{~ms}$

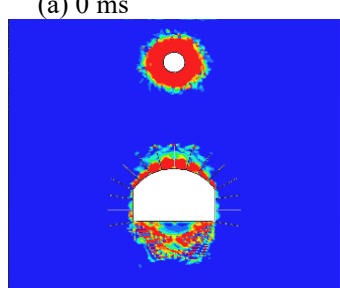

(f) $1.7 \mathrm{~ms}$

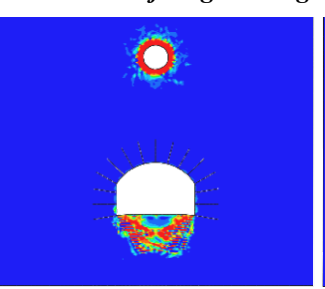

(b) $0.5 \mathrm{~ms}$

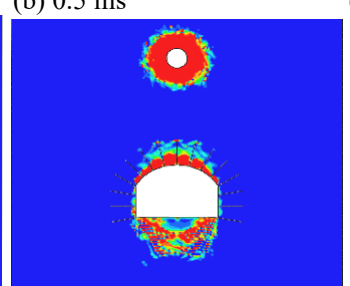

(g) $2.0 \mathrm{~ms}$

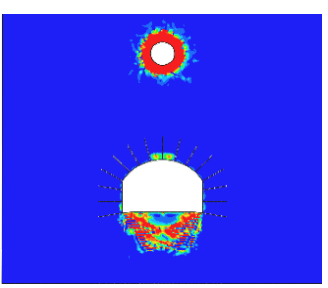

(c) $0.8 \mathrm{~ms}$

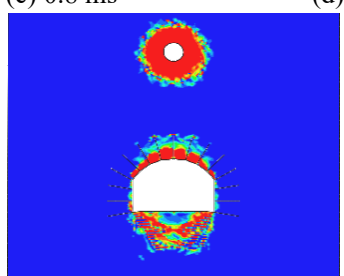

(h) $2.5 \mathrm{~ms}$

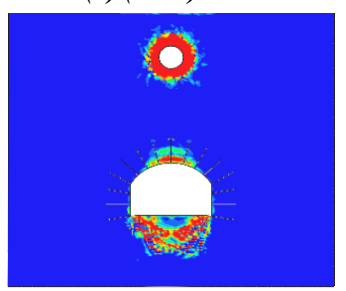

(d) $0.9 \mathrm{~ms}$

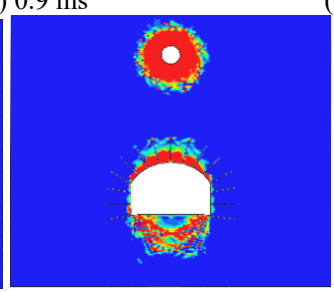

(i) $3.0 \mathrm{~ms}$

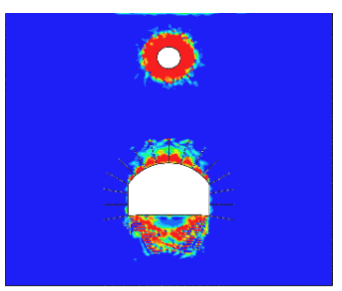

(e) $1.1 \mathrm{~ms}$ Damage $\boldsymbol{F}^{0.984} \begin{aligned} & 0.820 \\ & 0.656 \\ & 0.492 \\ & 0.328 \\ & 0.164 \\ & 0.000\end{aligned}$

Fig.7. Evolution diagram of tensile damage for the deep cavern under dynamic loading.

When the stress wave is applied for $0.5 \mathrm{~ms}$, a ring with the largest compression damage centered on the explosion source will be formed. With the stress wave propagating forward, at $0.8 \mathrm{~ms}$, the compressive stress wave has already propagated to the vault, and the range and intensity of compressive damage near the free surface of the vault are further strengthened. At $1.1 \mathrm{~ms}$, the maximum compression damage area appears at the head of bolt on the vault, and with the propagation of stress waves, the maximum compression damage area gradually extends upward and on both sides. The maximum compression damage area of the entire vault is mainly distributed near the free surface of the vault, and the maximum compression damage area from the vault to the spandrel is getting smaller and smaller. At 1.7 $\mathrm{ms}$, the maximum compressive damage area of the vault no longer changes. During the entire dynamic load process, the damage range and degree of floor hardly change, which is mainly caused by the static loading.

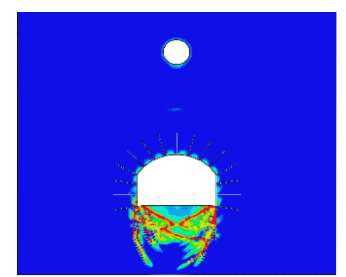

(a) $0 \mathrm{~ms}$

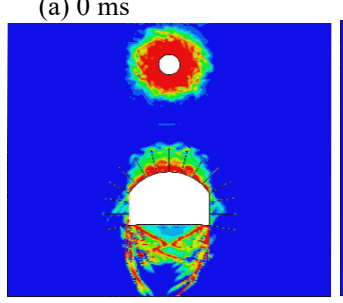

(f) $1.7 \mathrm{~ms}$

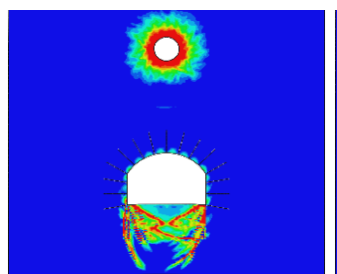

(b) $0.5 \mathrm{~ms}$

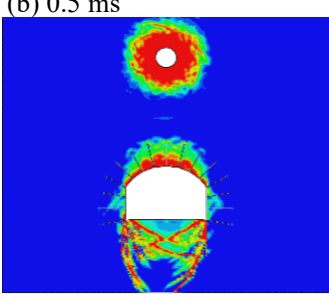

(g) $2.0 \mathrm{~ms}$

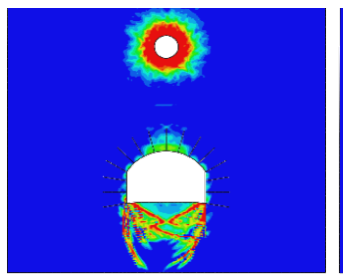

(c) $0.8 \mathrm{~ms}$

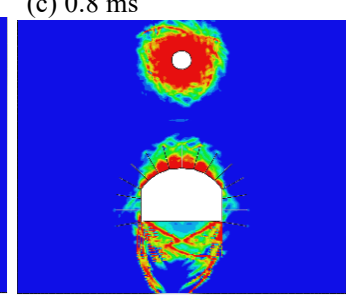

(h) $2.5 \mathrm{~ms}$

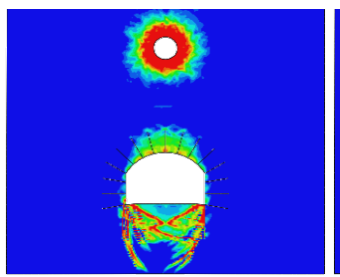

(d) $0.9 \mathrm{~ms}$

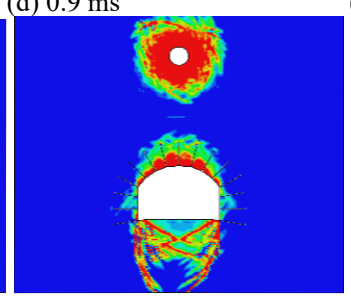

(i) $3.0 \mathrm{~ms}$

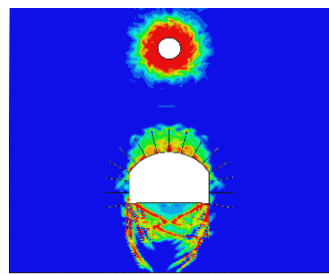

(e) $1.1 \mathrm{~ms}$

Damage

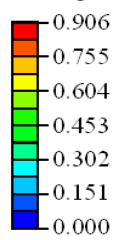

$L_{0.000}$

Fig. 8. Evolution of compression damage for the deep cavern under dynamic loading.

between the anchorage and the non-anchorage areas gradually decreases. Until the hydrostatic confining pressure is $1.75 \mathrm{MPa}$, the maximum tensile damage area at the junction of the anchorage and non-anchorage areas almost disappears, and the degree of the tensile damage of floor is first reduced and then increased. When the hydrostatic confining pressure is $1.50 \mathrm{MPa}$, the maximum tensile damage obviously appears under the floor.

With increase of the hydrostatic confining pressure, the maximum tensile damage under the floor increases gradually, and the location of the damage becomes deeper. When the hydrostatic confining pressure is $2.0 \mathrm{MPa}$, a large area of tensile damage is formed under the floor. In the case of deep anchoring caverns, special attention should be paid to tensile damage near the free surface of the vault. As the hydrostatic confining pressure increases, the tensile failure of the vault under dynamic load is from the overall collapse of the anchoring area to the local peeling off of the free surface of the cavern, and the floor heave is more and more serious. 
G.Y. Wang, T.T. Wang, S.R. Wang, Y.S. He, F.L. Kong and J.Q. Fan/

Journal of Engineering Science and Technology Review 13 (3) (2020) 96 - 105
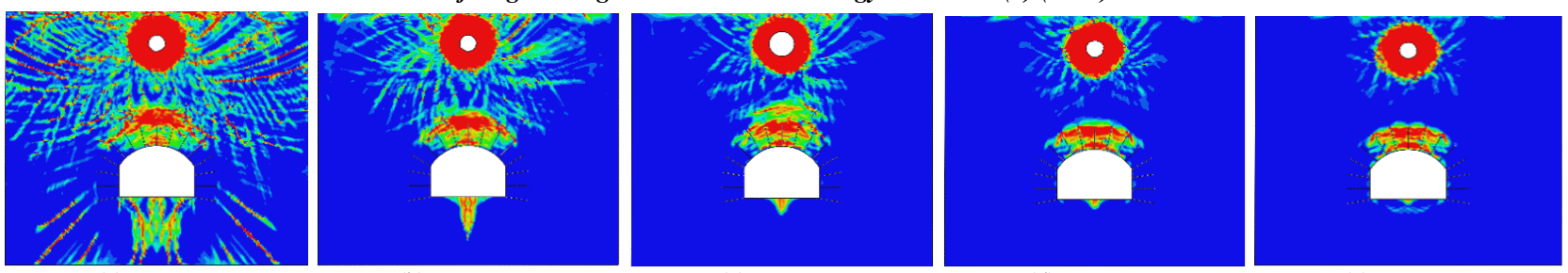

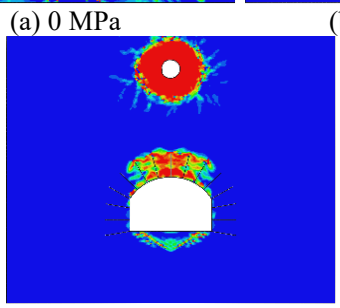

(f) $1.25 \mathrm{MPa}$

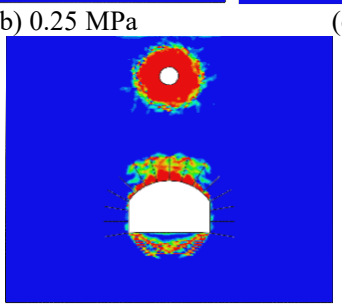

(g) $1.50 \mathrm{MPa}$

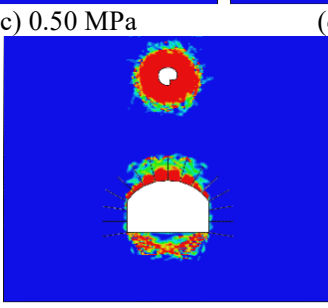

(h) $1.75 \mathrm{MPa}$

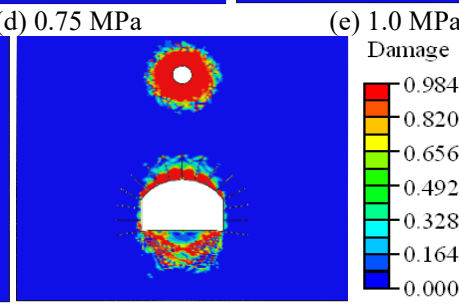

(i) $2.00 \mathrm{MPa}$

Fig. 9. Tensile damage diagram of anchorage cavern with different hydrostatic confining pressures under dynamic loading.

It can be seen from Fig. 10, as the hydrostatic confining pressure increases, the maximum tensile damage area of the vault decreases first and then increases. The maximum damage area of the vault without hydrostatic confining pressure is the largest, which is the smallest when the hydrostatic confining pressure is $0.50 \mathrm{MPa}$, and the damage area does not change significantly from $0.75 \mathrm{MPa}$ to 1.50 $\mathrm{MPa}$. When the hydrostatic confining pressure is less than 1.25 MPa, except that the maximum tensile damage area of the floor without hydrostatic confining pressure is $56.21 \mathrm{~cm}^{2}$, the damage area of the floor does not appear until the hydrostatic confining pressure is $1.25 \mathrm{MPa}$. As the hydrostatic confining pressure continues to increase to 2.0 $\mathrm{MPa}$, the damage area of the floor becomes larger, and the increase rate is more obvious. The maximum tensile damage area of the floor is $320.95 \mathrm{~cm}^{2}$ when the hydrostatic confining pressure is $2.0 \mathrm{MPa}$.

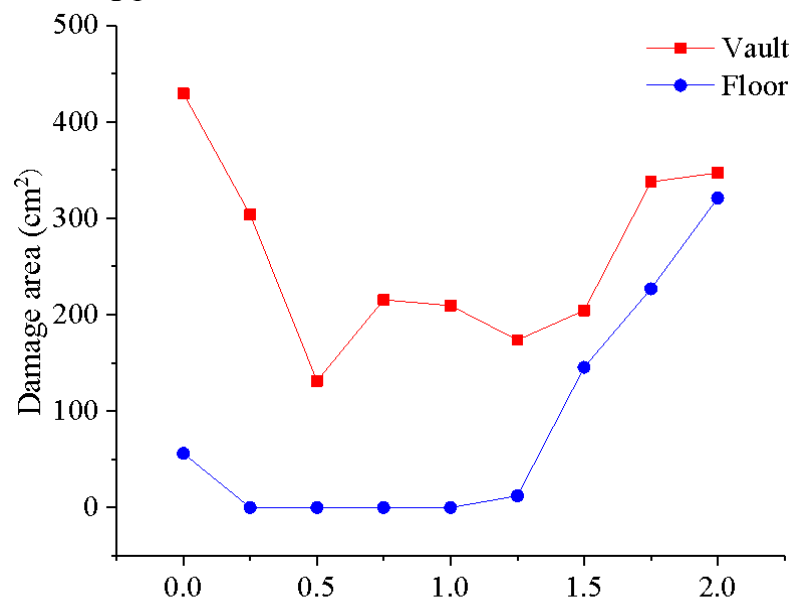

Hydrostatic confining pressure (MPa)

Fig. 10. The hydrostatic confining pressure and maximum tensile damage area of the vault and floor under dynamic loading.

The reason for the above phenomenon is that the surrounding rocks are mainly affected by pressure correlation and strain rate correlation. As the tensile strength of the rock masses increase with the increase of the hydrostatic confining pressure, the energy dissipation of the stress wave is smaller. On the other hand, the tensile strength of the rock masses increase with the increase of the dynamic strain rate. When the hydrostatic confining pressure is small, the influence of the hydrostatic confining pressure and strain rate on the tensile strength of the surrounding rock is more obvious than that of the hydrostatic confining pressure on the attenuation of the stress wave, so the maximum tensile damage area of the arch crown decreases first. With the increase of the hydrostatic confining pressure, the influence of the confining pressure on the attenuation of the stress wave is more obvious than that of the confining pressure and strain rate on the tensile strength of the surrounding rock, which leads to the increase of the maximum damage area of the vault between $0.5 \mathrm{MPa}$ and $2.0 \mathrm{MPa}$. Because the floor is less affected by the dynamic load, when the hydrostatic confining pressure reaches a certain value, the tensile stress in the local area under the floor reaches the tensile strength of the rock masses, and then with the increase of the hydrostatic confining pressure, the maximum tensile damage area of the floor increases obviously.

\subsubsection{Compression damage distribution characteristics}

It can be seen from Fig. 11, when there is no confining pressure, there is only relatively small compressive damage around the vault. With increase of the confining pressure, the compression damage of the vault becomes more serious. When the confining pressure is $1.25 \mathrm{MPa}$, the maximum compression damage begins to appear near the free surface of the vault. When the confining pressure does not exceed 1.5 $\mathrm{MPa}$, there is almost no damage to the floor. When the confining pressure reaches $1.5 \mathrm{MPa}$, a relatively narrow "V" shaped damage area begins to appear. With increase of confining pressure, the maximum compression damage at the floor becomes more complex, mainly extending from the corner to the depth, and gradually forming a piece from the line. Therefore, when the anchorage cavern is subjected to large confining pressure, it is necessary to pay attention to the compression damage near the free surface of the vault and floor, which may cause partial peeling of the vault and floor heave.

As shown in Fig. 12, with increase of the hydrostatic confining pressure, the maximum compressive damage area of the vault and the floor under dynamic loading did not appear before a certain confining pressure. As the hydrostatic confining pressure continued to increase, the maximum compressive damage area of the vault and the floor became larger, and their correlation with confining pressure is obvious. The maximum compressive damage area of the vault and floor appear about 1.00 and $1.25 \mathrm{MPa}$, respectively. Until the hydrostatic confining pressure is 2.0 $\mathrm{MPa}$, the maximum compressive damage area of the vault and floor is 225.7 and $516.5 \mathrm{~cm}^{2}$. Although the compressive strength of the surrounding rock is improved with increase of the hydrostatic confining pressure and the effect of strain rate, the increase of compressive stress caused by the 
G.Y. Wang, T.T. Wang, S.R. Wang, Y.S. He, F.L. Kong and J.Q. Fan/

Journal of Engineering Science and Technology Review 13 (3) (2020) 96 - 105

hydrostatic confining pressure and compressive stress wave on surrounding rock is obvious, so that when the hydrostatic confining pressure exceeds a certain value, the maximum
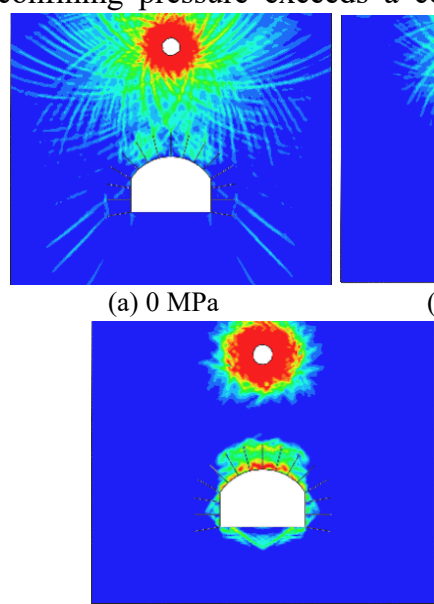

(f) $1.25 \mathrm{MPa}$

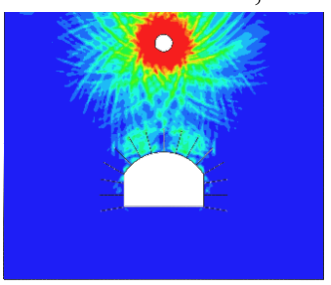

(b) $0.25 \mathrm{MPa}$

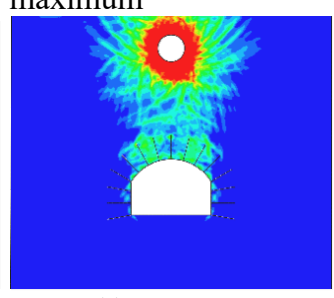

(c) $0.50 \mathrm{MPa}$

compressive damage area of the vault and floor becomes larger.

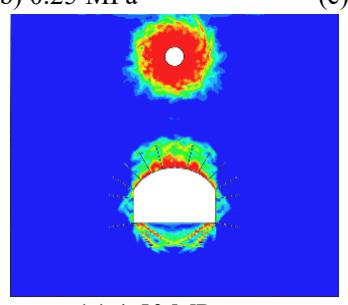

(g) $1.50 \mathrm{MPa}$

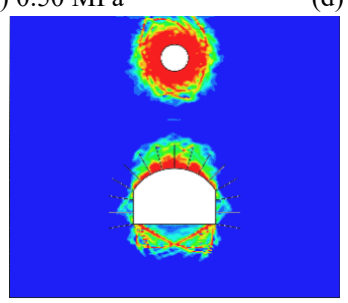

(h) $1.75 \mathrm{MPa}$

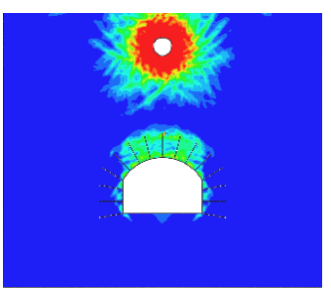

(d) $0.75 \mathrm{MPa}$

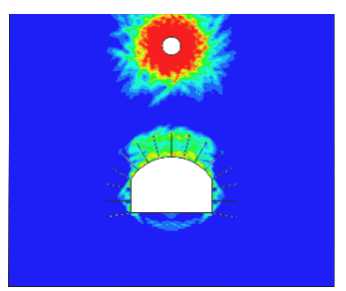

(e) $1.00 \mathrm{MPa}$

Fig. 11. Compressive damage of anchoring cav

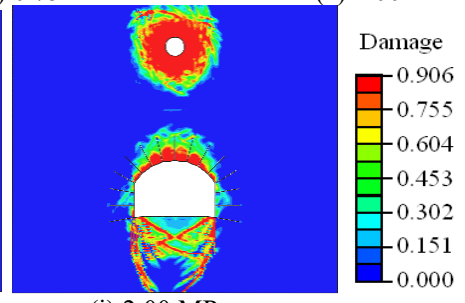

(i) $2.00 \mathrm{MPa}$

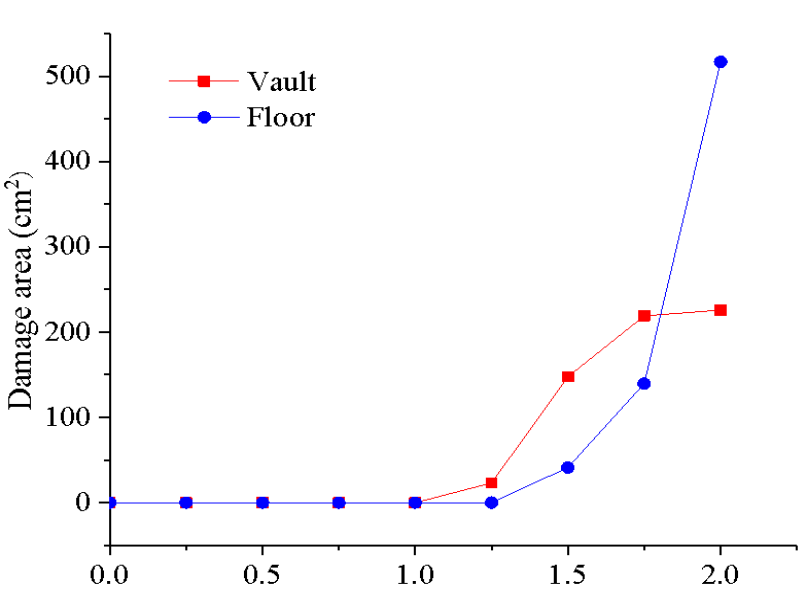

Hydrostatic confining pressure (MPa)

Fig. 12. The hydrostatic confining pressure and maximum compression damage area of the vault and floor under dynamic loading.

4.3 Damage of deep anchorage cavern with different lateral pressure coefficients under dynamic loading

\subsubsection{Tensile damage distribution characteristics}

Hoek \& Brown pointed out the estimation equation of the ratio $K$ of horizontal stress to vertical stress [28]:

$$
100 / Z+0.3<K<1500 / Z+0.5
$$

The depth selected in this study is $1200 \mathrm{~m}$. The range of the lateral pressure coefficient calculated according to Eq. (11) is $0.38-1.75$, so the lateral pressure coefficients are taken as $0.4,0.6,0.8,1.0,1.25,1.50$, and 1.75. Figs. 13 and 14 are the final tensile damage of the anchoring cavern with different lateral pressure coefficients under the dynamic loading and static loading.

Comparing Figs. 13 and 14, it can be known that the tensile damage of the vault is mainly affected by the

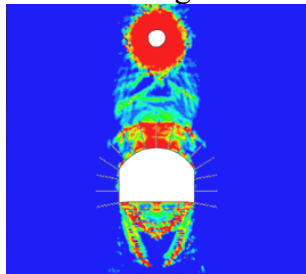

(a) 0.4

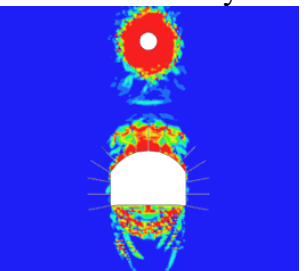

(b) 0.6

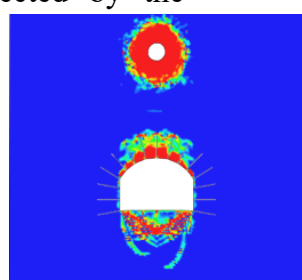

(c) 0.8

dynamic loading, while the floor is closely related to the static loading. When the lateral pressure coefficient is 0.4 , the maximum tensile damage area will be formed in the anchorage area at the three bolts directly above the vault, and the entire zone is penetrated. The maximum tensile damage in other parts of the vault is mainly distributed near the free surface and the junction of the anchorage and the non-anchorage areas. Until the lateral pressure coefficient is 1.0 , as the lateral pressure coefficient gradually increases, the area of the maximum tensile damage near the free surface of the vault gradually increases and extends to both sides. When the lateral pressure coefficient is greater than 1.0, the maximum tensile damage area near the free surface has developed to the sidewall.

With increase of the lateral pressure, the tensile damage of the anchorage area gradually weakened, and the maximum tensile damage area at the junction of the anchorage and the non-anchorage areas gradually decreased. When the lateral pressure coefficient is 1.0, the maximum damage area at the junction of anchorage and non-anchorage zones disappears. When the lateral pressure is relatively small, the local area directly above the cavern will be penetrated due to tension, leading to the collapse of the underground cavern. With increase of the lateral pressure, only the maximum tensile damage near the free surface of the vault of the underground cavern will occur, which indicates that local peeling will occur. When the lateral pressure is relatively small, the lateral pressure coefficient is 0.4 , "V" and trumpet shaped maximum tensile damage appear under the floor. With increase of the lateral pressure coefficient, the trumpet shaped maximum tensile damage gradually weakens until it disappears, and the area of the maximum tensile damage of the "V" shape becomes larger, and the damage of the sidewall bottom is more serious, which may cause the floor heave.

Fig. 13. Tensile damage of anchorage cavern with different lateral pressure coefficients under dynamic loading.

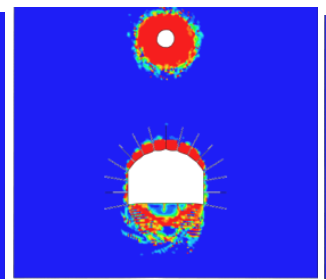

(d) 1.25

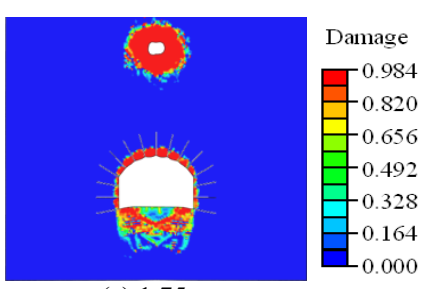

(e) 1.75 


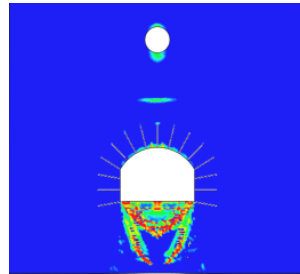

(a) 0.4

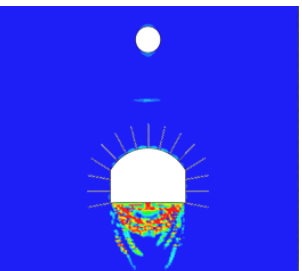

(b) 0.6

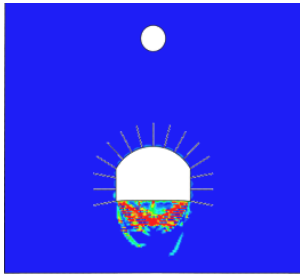

(c) 0.8

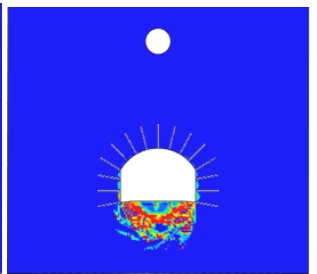

(d) 1.25

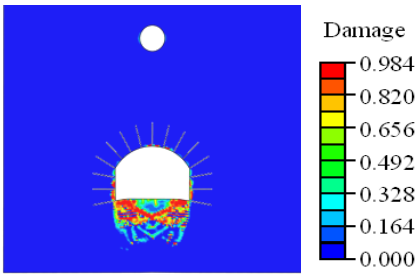

(e) 1.75

Fig. 14. Tensile damage of anchorage cavern with different lateral pressure coefficients under static loading.

As shown in Fig. 15, the maximum tensile damage area of the vault, floor and sidewall of the anchorage cavern. Except when the lateral pressure coefficient is 0.4, with increase of the lateral pressure coefficient, the maximum tensile damage area of the vault first increases and then decreases, and the damage area of the vault with the lateral pressure coefficient of 1.25 is the largest. With increase of the lateral pressure, the maximum tensile damage area of the floor increases first and then decreases, and when the coefficient of the lateral pressure is between 1.0-1.2, the maximum tensile damage area of the floor is the larger. With increase of the lateral pressure, the maximum tensile damage area of the sidewall does not appear until the lateral pressure coefficient reaches 1.0. With the further increase of the lateral pressure, the maximum tensile damage area of the sidewall becomes larger, increasing more obvious.

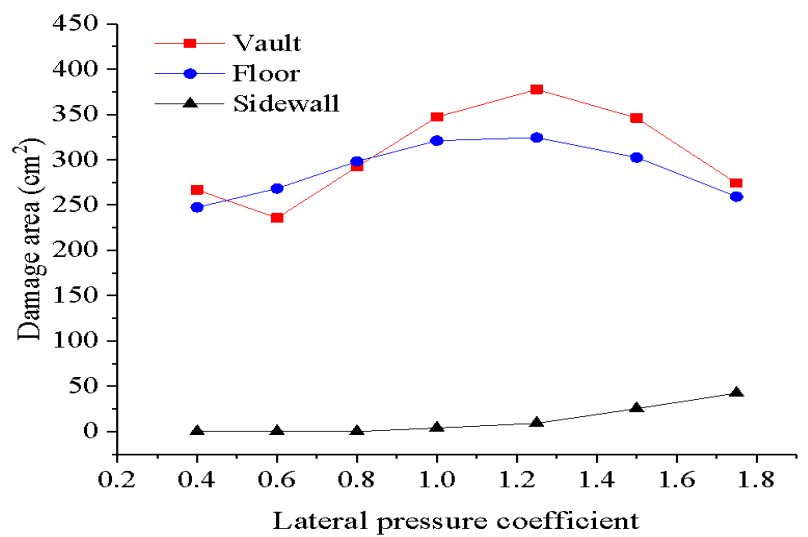

Fig. 15. Different lateral pressure coefficients and the maximum tensile damage area of the vault, floor and sidewall under dynamic loading.

\subsubsection{Compression damage distribution characteristics} The compression damage distributions of the deep anchorage cavern under different lateral pressures under the dynamic loading and static loading are shown in Figs. 16 and 17.

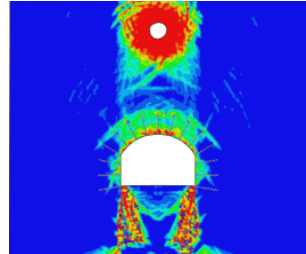

(a) 0.4

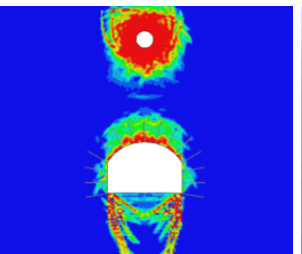

(b) 0.6

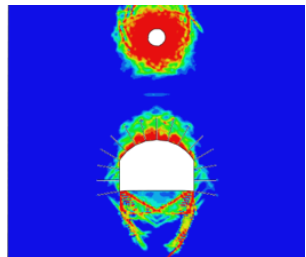

(c) 0.8
Comparing Figs. 16 and 17, it can be found that the static loading mainly affects the damage distribution of the floor. Only when the lateral pressure coefficient reaches 1.75 , the maximum compressive damage occurs in the vault of the cavern, while the maximum compressive damage of the vault and sidewall is mainly affected by dynamic loading. When the lateral pressure coefficient is 0.4 , there is a relatively thin damage area near the free surface of the vault, and two relatively narrow maximum compressive damage areas are formed within the range of $60^{\circ}-90^{\circ}$ of the corner. When the lateral pressure coefficient is 1.25 , the maximum compression damage band appears directly above the vault. As the lateral pressure further increases, the maximum compression damage band of the vault gradually extends upwards, and eventually communicated with the damage area near the explosion source, causing the entire collapse from the explosion source to the anchorage cavern. With increase of the lateral pressure, the maximum compressive damage at the corner approaches to the middle of the floor, forming a crisscross "V" shape network distribution. When the lateral pressure coefficient exceeds 1.0, the maximum compressive damage in a small area will occur in the sidewall.

As shown in Fig. 18, the maximum compressive damage area at the vault and floor is significantly larger than that of the sidewall. With increase of the lateral pressure coefficient, the maximum compressive damage area of the vault under dynamic load becomes larger. Because the static compressive effect on the vault is getting larger, causing the maximum compressive damage area of the vault is growing faster. With increase of the lateral pressure, the maximum compressive damage area of the floor first decreases and then increases. When the lateral pressure coefficient is 0.8 , the maximum compressive damage area is the smallest. The maximum compression damage of the sidewall appears after the lateral pressure coefficient is 1.0 , and slowly increases with the increase of the lateral pressure coefficient.

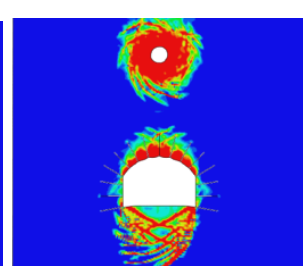

(d) 1.25

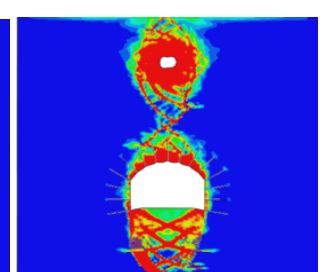

(e) 1.75

Fig. 16. Compression damage of anchorage cavern with different lateral pressure coefficients under dynamic loading.

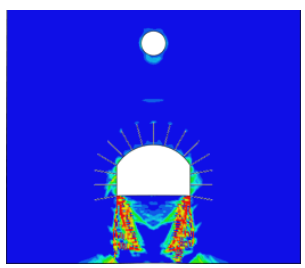

(a) 0.4

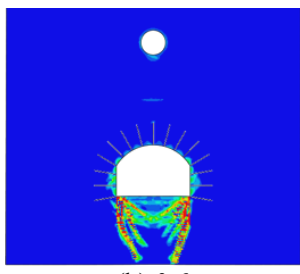

(b) 0.6

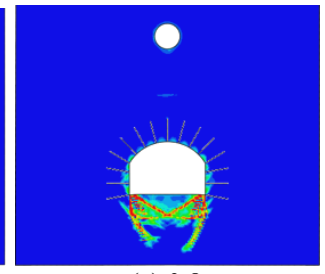

(c) 0.8

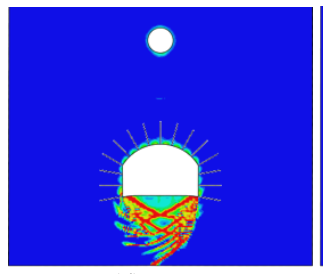

(d) 1.25

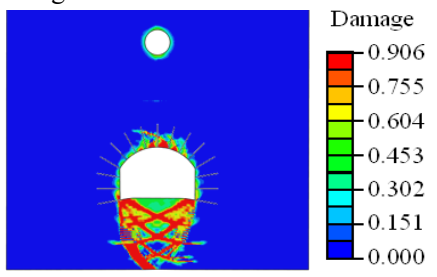

(e) 1.75

Fig. 17. Compression damage of anchorage cavern with different lateral pressure coefficients under static loading. 


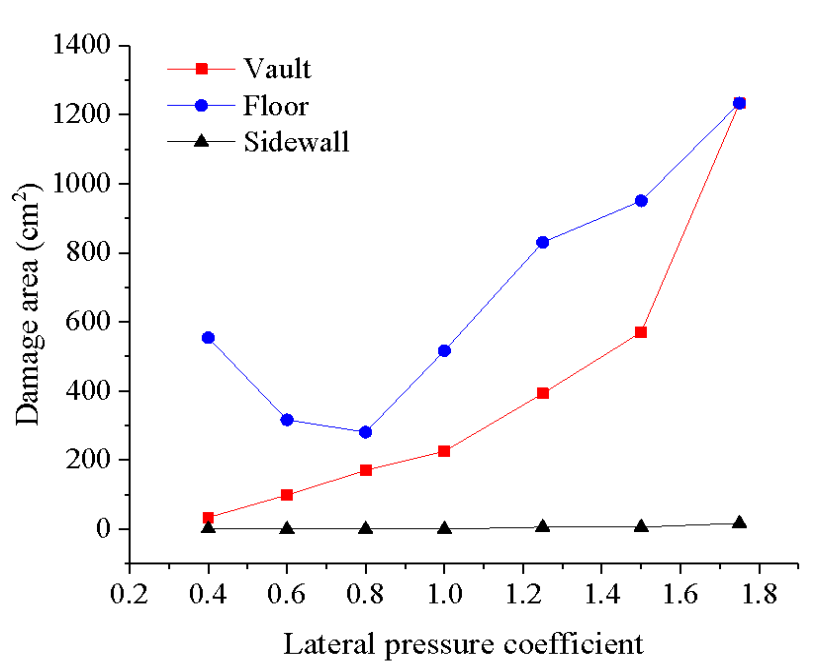

Fig. 18. Lateral pressure coefficients and the compressive damage area.

\section{Conclusions}

To reveal the damage evolution characteristics of the surrounding rock in deep anchorage cavern under dynamic loading, based on the similarity model test, the damage evolution of the anchorage cavern under different in-situ stress was analyzed by numerical simulation. The main conclusions are as follows.

(1) When the deep anchorage cavern is subjected to the dynamic loading above the vault, the tensile and compressive damage of the vault is significantly affected by the dynamic load, while the tensile and compressive damage of the floor is little affected. With the propagation of stress wave, the maximum tensile and compressive damage area gradually extends from the free surface of the vault upward and on both sides, and finally tends to stable.

(2) When the deep anchorage cavern is subjected to dynamic-static coupling loading, the maximum tensile damage area mainly appears near the free surface of the vault, the junction of the anchorage and the non-anchorage areas of the vault, and the floor. With increasing of the hydrostatic confining pressure, the maximum tensile damage area near the free surface of the vault increases gradually, the maximum tensile damage area at the junction of the anchorage and the non-anchorage areas decreases gradually, and the degree of tensile damage of the floor is first decreasing and then increasing.
(3) With increase of the hydrostatic confining pressure, the maximum compression damage of the vault and the floor occurs after the hydrostatic confining pressure reaches 1.0 and $1.25 \mathrm{MPa}$, respectively. The maximum compressive damage areas of the vault and the floor are getting larger, and shows a clear correlation with the hydrostatic confining pressure. With increase of the lateral pressure coefficient, the maximum tensile damage area near the free surface of the vault first increases and then decreases gradually, and extends to the sidewall on both sides. The damage of the anchorage area decreases gradually, and the maximum tensile damage area at the junction of the anchorage and the non-anchorage areas also decreases gradually. The maximum tensile damage area of the side wall is getting larger.

(4) The maximum compression damage only occurs near the free surface of the vault. As the lateral pressure coefficient gradually increases, the maximum compressive damage near the free surface of the vault gradually thickens. Subsequently, the maximum compression damage strip appears directly above the vault. The damage strip gradually extends upward and finally connects with the maximum compression damage near the explosion source. With increase of the lateral pressure, the maximum compression damage area of the floor first decreases and then increases. When the lateral pressure coefficient is 0.8 , the maximum compression damage area of floor is the smallest. The maximum compression damage of the sidewall appears after the lateral pressure coefficient is 1.0 , and increases gradually with the increase of the lateral pressure coefficient.

This study can provide references for the support of the deep cavern. Since the test model is based on the civil air defense cavern as the prototype, the surrounding rocks are relatively uniform and intact, therefore, the inhomogeneity and discontinuity of the surrounding rock should be considered in the further study.

\section{Acknowledgements}

This study was financially supported by the National Natural Science Foundation of China (51774112), the International Cooperation Project of Henan Science and Technology Department (182102410060), the Doctoral Fund of Henan Polytechnic University (B2015-67).

This is an Open Access article distributed under the terms of the Creative Commons Attribution License

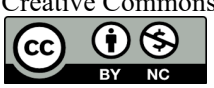

\section{References}

1. Abdul, M. N., Muhammad, Z. E., Hafeezur, R., Hankyu, Y., "Geological and geomechanical heterogeneity in deep hydropower tunnels: A rock burst failure case study". Tunnelling and Underground Space Technology, 84, 2019, pp. 507-521.

2. Li, X. B., Gong, F. Q., Tao, M., Dong, L. J., Du, K., Ma, C. D., Zhou, Z. L., Yin, T. B., "Failure mechanism and coupled static-dynamic loading theory in deep hard rock mining: A review". Journal of Rock Mechanics and Geotechnical Engineering, 9, 2017, pp. 767782.

3. Xie, L. X., Lu, W. B., Zhang, Q.B., Jiang, Q. H., Wang, G.H., Zhao, J., "Damage evolution mechanisms of rock in deep tunnels induced by cut blasting". Tunnelling and Underground Space Technology, 58, 2016, pp. 257-270.
4. Lee, J. H., Jae, H. H., Lee, Y. J., Lee, H. J., "Separation characteristics study of ridge-cut explosive bolts". Aerospace Science and Technology”, 39, 2014, pp.153-168.

5. Mortazavi, A., Tabatabaei, A. F., "A numerical study of the behavior of fully grouted rockbolts under dynamic loading ". Soil Dynamics and Earthquake Engineering, 54, 2013, pp. 66-72.

6. Chang, X., Wang, G. Y., Tang, C. N., Ru, Z. L., "Dynamic behavior of cement-mortar cavern reinforced by bars". Engineering Failure Analysis, 55, 2015, pp. 343-354.

7. Gu, J.C. Chen, A. M., Xu, J. M., "Model test study of failure patterns of anchored tunnel". Chinese Journal of Rock Mechanics and Engineering, 27(7), 2008, pp. 1315-1320.

8. Singh, P. K., "Blast vibration damage to underground coal mines from adjacent open-pit blasting". International Journal of Rock Mechanics \& Mining Sciences, 39 (8), 2002, pp. 959-973. 
G.Y. Wang, T.T. Wang, S.R. Wang, Y.S. He, F.L. Kong and J.Q. Fan/

\section{Journal of Engineering Science and Technology Review 13 (3) (2020) 96 - 105}

9. Wang, H. W., Jiang, Y. D., Xue, S., "Assessment of excavation damaged zone around roadways under dynamic pressure induced by an active mining process". International Journal of Rock Mechanics \& Mining Sciences, 77, 2015, pp. 265-277.

10. Xu, G. C., Yuan, W. Z., Gu, J. C., "Explosive resistivity of anchored cavern surface rock". Chinese Journal of Rock Mechanics and Engineering, 34(9), 2015, pp. 1767-1776.

11. Xu, J. M. Gu, J. C., Chen, A. M., "Model test study of antiexplosion capacity of anchored tunnel with local lengthening anchors in arch springing". Chinese Journal of Rock Mechanics and Engineering, 31(11), 2012, pp. 2182-2186.

12. Wang, S. R., Xiao, H. G., Hagan, P., Zou, Z. S., "Mechanical behavior of fully-grouted bolt in jointed rocks subjected to double shear tests". DYNA, 92(3), 2017, pp. 314-320.

13. Wang, Z. Y., Dou, L. M., Wang, G. F., "Failure mechanism of anchored bolt supporting structure of circular roadway under dynamic load". Chinese Journal of Geotechnical Engineering, 37(10), 2015, 1901-1909.

14. Mortazavi, A., Fatemeh, T. A., "numerical study of the behavior of fully grouted rockbolts under dynamic loading". Soil Dynamics and Earthquake Engineering, 54, 2013, pp. 66-72.

15. Zhou, H., Xiao, M., Chen, J. T., "Analysis of a numerical simulation method of fully grouted and anti-seismic support bolts in underground geotechnical engineering". Computers and Geotechnics, 76, 2016, pp. 61-74.

16. Deng, X. F., Zhu, J. B., Chen, S. G., "Numerical study on tunnel damage subject to blast-induced shock wave in jointed rock masses". Tunnelling and Underground Space Technology, 43(6), 2014, pp. 88-100.

17. Nick, Y., Woo, S., "Analysis of blasting damage in adjacent mining excavations". Journal of Rock Mechanics and Geotechnical Engineering, 7(3), 2015, pp. 282-290.

18. Ortlepp, W. D., Stacey, T. R., "Performance of tunnel support under large deformation static and dynamic loading". Tunnelling and underground space technology, 13(1), 1998, pp. 15-21.
19. Wu, Y. Z., Chen, J. Y., Jiao, J. K., "Damage and failure mechanism of anchored surrounding rock with impact loading”. Journal of China Coal Sooiety, 43(9), 2018, pp. 2389-2397.

20. Li, X. B., Weng, L., "Numerical investigation on fracturing behaviors of deep-buried opening under dynamic disturbance". Tunnelling and Underground Space Technology, 54, 2016, pp. 6172.

21. Li, C. J., Li, X. B., "Influence of wavelength-to-tunnel-diameter ratio on dynamic response of underground tunnels subjected to blasting loads". International Journal of Rock Mechanics and Mining Sciences, 112, 2018, pp. 323-338.

22. Li, X. B., Li, C. J., Cao, W. Z., Tao, M., "Dynamic stress concentration and energy evolution of deep-buried tunnels under blasting loads". International Journal of Rock Mechanics and Mining Sciences, 104, 2018, pp. 131-146.

23. Wang, X. W., Xiong, Q. R., Zhou, H., Chen, J. T., Xiao, M., "Three-dimensional dynamic finite element modeling of the effects of a geological fault on the seismic response of underground caverns". Tunnelling and Underground Space Technology, 96, 2020, pp. 103-110.

24. Wang, H. B., Zhang, H. B., Tian, Z., "Mesh Size Effect and Its Mechanism Research in Numerical Calculation of Rock Dynamics". Acta Armamentarii, 37(10), 2016, pp. 1828-1836.

25. Lubliner, J., Oliver, J., Oller, S., "A Plastic-damage model for concrete". International Journal of Solids and Structures, 25(3), 1989, pp. 299-326.

26. Lee, J., Fenves, G. L., "Plastic -damage model for cyclic loading of concrete structures". Journal of Engineering Mechanics, 124(8), 1998, pp. 892-900.

27. Price, R. H., Boyd, P. J., Noel, J. S., "Relation between static and dynamic rock properties in welded and nonwelded tuff'. SAND-940306C [R]. Office of Scientific \& Technical Information Technical Reports, 1994.

28. Hoek, E., Browm, E. T., "Underground excavations in rock". London: Institution of Mining and Metallurgy, 1980, pp. 30-70. 